\title{
Gemtuzumab ozogamicin and novel antibody-drug conjugates in clinical trials for acute myeloid leukemia
}

\author{
Bo Yu ${ }^{1}$ and Delong Liü $2,3^{*}$
}

\begin{abstract}
Targeted agents are increasingly used for the therapy of acute myeloid leukemia (AML). Gemtuzumab ozogamicin (GO) is the first antibody-drug conjugate (ADC) approved for induction therapy of AML. When used in fractionated doses, GO combined with the conventional cytarabine/anthracycline-based induction chemotherapy significantly improves the outcome of previously untreated AML patients. Single-agent GO is effective and safe for AML patient ineligible for intensive chemotherapy. Multiple combination regimens incorporating $\mathrm{GO}$ have also been recommended as potential alternative options. In addition, several novel ADCs targeting CD33, CD123 and CLL-1 are currently undergoing preclinical or early clinical investigations. In this review, we summarized the efficacy and limitations of $G O$ as well as novel ADCs for adult AML patients.
\end{abstract}

Keywords: Gemtuzumab ozogamicin, Antibody-drug conjugate, CD33, CD123, CLL1

\section{Introduction}

The prognosis of AML remains unsatisfactory with a 5year overall survival (OS) rate of $40 \%$ for patients less than 60 years of age and only $10 \%$ for elderly patients above the age of 60 [1]. The conventional first-line treatment of AML includes intensive cytarabine/anthracycline-based induction chemotherapy followed by consolidation chemotherapy or allogenic stem cell transplantation (AlloSCT) [2-6]. Best supportive care, low dose cytarabine, and hypomethylating agents (HMA) are often alternative options for elderly patients unfit for intensive chemotherapy [7]. In the past several years, several new targeted agents against FLT3, IDH1, and IDH2 have been approved for AML therapy [8-16]. Novel targeted therapies and immunotherapies against AML are in active clinical development [17-20]. One such example is gemtuzumab ozogamicin (GO), an antibodydrug conjugate $(\mathrm{ADC})$ [21-24].

ADC composes of three essential components: a monoclonal antibody (mAb) that recognizes an antigen

\footnotetext{
*Correspondence: delong_liu@nymc.edu

${ }^{2}$ Department of Medicine, New York Medical College and Westchester Medical Center, Valhalla, NY, USA

${ }^{3}$ Department of Oncology, The First affiliated Hospital of Zhengzhou

University, Zhengzhou, China

Full list of author information is available at the end of the article
}

target on tumor cells, a cytotoxic molecule often referred to as payload, and a chemical linker that connects the $\mathrm{mAb}$ and payload [25-28]. Upon binding to the corresponding antigen on the surface of tumor cells, ADC is internalized first and the linker is hydrolyzed inside of the lysosomes or endosomes, releasing the payloads that lead to cell death by damaging DNA or impeding microtubule assembly. ADC becomes attractive because it enhances targeted killing of tumors while sparing normal tissues, thereby minimizing toxicity. With the improvement of engineering technology, the newest generation of ADC can be generated through site-specific conjugation and has homogenous drug-antibody ratio as well as better stability in circulation [29]. This review summarized the recent updates of GO and other ADCs at different stages of development for AML therapy.

\section{Gemtuzumab ozogamicin (GO; Mylotarg) Clinical pharmacology}

GO is a humanized anti-CD33 IgG4 mAb conjugated to a cytotoxic agent $\mathrm{N}$-acetyl gamma calicheamicin via an acid-labile hydrazone linker [29]. CD33 belongs to the family of sialic acid-binding immunoglobulin-like lectins (Siglecs). It is a transmembrane glycoprotein expressed on the surface of immature cells of myelomonocytic 
lineage and myeloblasts in $>80 \%$ of AML patients [30]. High CD33 expression is generally correlated to negative prognostic features [31]. Specifically targeting CD33 does not affect the differentiation of presumably normal CD33-CD34+ myeloid progenitors, allowing for the restoration of normal nonclonal hematopoiesis [32, 33]. Upon binding to CD33, the drug is quickly internalized. Calicheamicin is released in the acidic environment of lysosomes and then binds to DNA, resulting in DNA double-strand breaks and subsequent cell death.

A phase I dose escalation study for GO in CD33+ AML was done with $0.25-9 \mathrm{mg} / \mathrm{m}^{2}$ for two doses 14 days apart. The maximum tolerated dose (MTD) was determined to be $9 \mathrm{mg} / \mathrm{m}^{2}$, which was recommended for further phase II trials. Infusion reaction, myelosuppression, and bilirubin elevation were generally observed at MTD [34]. Pharmacokinetic studies showed larger than proportional increases in maximum concentration (Cmax) and area under the time-concentration curve (AUC) with escalating dose of GO. There was a remarkable decrease in clearance with subsequent doses, as the half-life of GO was 62 hour (h) after the first $9 \mathrm{mg} / \mathrm{m}^{2}$ dose and $90 \mathrm{~h}$ after the second dose. Increase in Cmax was associated with a higher risk of hepatotoxicity, but no relationship between Cmax or AUC and complete remission (CR) rate was discovered. Therefore, responses to GO are not strictly dose dependent, particularly at high dose ranges [35].

\section{Clinical trials of GO in AML}

GO received accelerated approval from FDA in 2000 based on the encouraging result of three open-label, multicenter, single arm phase II trials that enrolled 142 patients aged 60 or older in the first relapse of CD33+ AML treated with $9 \mathrm{mg} / \mathrm{m}^{2}$ of $\mathrm{GO}$ at 2-week intervals for 2 doses. There was a $30 \%$ overall response rate (ORR) with a $16.2 \% \mathrm{CR}$ rate [36]. In a post-approval phase III trial (SWOG S0106; NCT00085709), newly diagnosed AML patients (aged 18 to 60 years) were randomized to receive either a single dose of GO $6 \mathrm{mg} / \mathrm{m}^{2}$ on day 4 in conjunction with the conventional ' $3+7$ ' DA induction chemotherapy (daunorubicin $45 \mathrm{mg} / \mathrm{m}^{2}$ on days $1-3$ and cytarabine or AraC $100 \mathrm{mg} / \mathrm{m}^{2}$ on days $1-7$, the DA regimen), or only DA but with $60 \mathrm{mg} / \mathrm{m}^{2}$ of daunorubicin (DNR) to balance the toxicity between groups. The addition of GO not only failed to improve CR rate, OS and event free survival (EFS) rate, but was associated with a higher early mortality during induction $(5.5 \%$ vs $1.4 \%)$. Major causes of death were fatal hemorrhage and infection [37]. The safety and efficacy concern led to a quick withdrawal of GO from the market in 2010. A subsequent prospective randomized trial (NCRI AML17; ISRCTN55675535) revealed that when incorporating $\mathrm{GO}$ into the induction therapy of previously untreated AML, a single dose of $6 \mathrm{mg} / \mathrm{m}^{2}$ appeared not superior to a $3 \mathrm{mg} / \mathrm{m}^{2}$ dose with respect to clinical response and survival but was associated with an increased risk of hepatotoxicity and early mortality [38]. The GO doses selected by previous studies including SWOG S0106 aimed at saturating target CD33 antigen after a single dose. However pharmacokinetic studies have discovered a $90 \%$ saturation of CD33 even at a lower dose $\left(3 \mathrm{mg} / \mathrm{m}^{2}\right)$, and a rapid recycling and reexpression of CD33 on cell surface within $72 \mathrm{~h}$ after the first exposure to the drug, hence a lower but frequent dosing schedule was thought to be safer and more beneficial [39]. Over the past decade, several investigational studies using fractionated dosing schedule of GO were completed and were able to improve the safety profiles without compromising the clinical efficacy [21, 40,41]. Based on these promising results, GO gained re-approval from FDA in September 2017 as monotherapy or in combination with conventional chemotherapy for the treatment of newly-diagnosed CD33+ AML and relapsed or refractory (R/R) CD33+ AML in adults [35, 42].

1.) $\mathrm{GO}+$ chemotherapy as induction regimen for newly diagnosed AML

ALFA-0701 (registered with EudraCT, number 2007002933-36) was one of the first phase III, open-label, randomized, multicenter trials evaluating $\mathrm{GO}$ administered in fractionated doses in conjunction with DA induction chemotherapy for newly diagnosed AML [40]. Two hundred seventy-one patients aged 50-70 with previously untreated AML were randomized to receive intensive doses of DA with or without GO $3 \mathrm{mg} / \mathrm{m}^{2}$ every $72 \mathrm{~h}$ on day 1,4 , and 7 . Patients who achieved CR continued to undergo 2 cycles of consolidation therapy that consisted of intermediate doses of DA with or without GO $3 \mathrm{mg} / \mathrm{m}^{2}$ on day 1 of each of the 2 consolidation cycles in accordance with the initial randomization. GO recipients experienced a longer median EFS (17.3 vs 9.5 months), a higher 3 -year EFS rate (39.8\% vs $13.6 \%)$, and a longer median relapse free survival (RFS) (28 vs 11.4 months). Subgroup analysis showed that the clinical benefits on EFS and RFS were restricted to patients with favorable or intermediate-risk cytogenetics. The median OS was slightly improved in GO recipients according to the interim results, but the difference failed to reach statistical significance in the final updates of the study (27.5 vs 21.8 months, $p=0.16$ ). No significant difference of $\mathrm{CR}$ or $\mathrm{CR}$ with incomplete platelet recovery (CR/CRi) after induction treatment was found between the GO and control arm $(81 \%$ vs $75 \%, p=0.25)$. Contrary to SWOG S0106, the number of early mortalities was similar [6 (4.6\%) vs $5(3.6 \%)]$ [40, 43]. A total of 85 patients in the study underwent AlloSCT, similar post- 
transplantation outcome and toxicity profile were observed in patients treated with and without GO [44]. Likewise, a meta-analysis of 3325 patients with newly diagnosed AML who were treated by GO + DA from 5 randomized controlled trials (RCT) (ALFA-0701, [40] SWOG S0106, [37] MRC AML15, [45] NCRI AML16, [23] and GOELAMS AML 2006 IR [46]) further confirmed that the addition of GO significantly reduced the risk of relapse and improved the 5-year OS. The survival benefit was also evident in patients with favorable or intermediate-risk cytogenetics, but not in those with high-risk cytogenetics. A lower incidence of early mortality was also identified in $3 \mathrm{mg} / \mathrm{m}^{2}$ dosed patients than $6 \mathrm{mg} / \mathrm{m}^{2}$ dosed patients [47]. A recent AML mouse model study suggested that the survival benefit seen with the combination of GO and DA might stem from an enhanced reduction of the leukemic stem cells (LSC) [48]. LSC was believed to be one of the leading causes of resistance to chemotherapy, persistence of measurable residual diseases (MRD) and relapse after CR [49].

Apart from $\mathrm{GO}+\mathrm{DA}$, various combination regimens have been studied or currently under development as frontline therapies for newly diagnosed AML (summarized in Table 1). There were attempts centered on modifying daunorubicin and cytarabine doses and adding new targeted agents or non- multidrug resistance (MDR) related drugs such as fludarabine. For example, in a recent phase II trial (NCT00909168), low dose GO $\left(3 \mathrm{mg} / \mathrm{m}^{2}\right.$ on day 6$)$ with fludarabine, cytarabine, granulocyte colony stimulating factor and idarubicin (FLAGIda) were administered to 130 patients under 65 years old. $82 \%$ of patients achieved CR, and the 2 -year OS and disease-free survival (DFS) were 63 and 54\% respectively. $63.8 \%$ of patients underwent AlloSCT after the induction therapy [50]. GO was studied in the EORTC-GIMEM AML-17 trial, a randomized trial that evaluated the GO therapy followed by standard chemotherapy, MICE (mitoxantrone, cytarabine, etoposide) in older patients (age 61 to 75 years) with newly diagnosed AML [51]. In the arm with GO, two doses of GO $(6 \mathrm{mg} / \mathrm{m}(2)$ on days 1 and 15) were given. For those patients in remission, two courses with or without GO $(3 \mathrm{mg} / \mathrm{m}(2)$ on day 0$)$ were given for consolidation. OS was the primary end point. In this study, 472 patients were enrolled. The ORR was similar (GO, 45\%; no GO, 49\%). However, the mortality rates were higher in the GO arm during induction and at day $60(17 \%$ v 12 and $22 \%$ v $18 \%$, respectively). Severe liver and hematologic toxicities were higher in the GO arm. Therefore, the sequential combination of GO and MICE chemotherapy had no survival benefit but worse toxicities for older patients with AML. For older patients who were ineligible for intensive chemotherapy, GO was proposed as a first-line monotherapy by a randomized phase III EORTC-GIMEMA
AML-19 trial (NCT00091234). In this study, 237 patients aged above 60 were randomized to receive either GO $\left(6 \mathrm{mg} / \mathrm{m}^{2}\right.$ on day 1 and $3 \mathrm{mg} / \mathrm{m}^{2}$ on day 8$)$ or best supportive care. GO recipients experienced a longer median OS (4.9 vs 3.6 months) and a higher 1-year OS rate $(24.3 \%$ vs $9.7 \%)$, while presenting with similar rates of adverse events (AE). The clinical outcome was consistent across all genetic subgroups [21]. Nevertheless, GO + DA still appeared to be the regimen that generated the best clinical outcome so far. In a recent meta-analysis, $\mathrm{GO}+\mathrm{DA}$ was compared to most other induction therapy agents for newly diagnosed AML. GO + DA was associated with significantly longer OS and RFS compared with most evaluated regimens, but a higher rate of hemorrhage and hepatotoxicity [52].

2.) $\mathrm{GO}+/$ - chemotherapy as re-induction regimen for relapsed or refractory AML

In the relapsed setting, $\mathrm{GO}$ was also effective and safe according to MyloFrance 1, a single-arm phase II trial. In this study, fractionated $\mathrm{GO}\left(3 \mathrm{mg} / \mathrm{m}^{2}\right.$ on days 1,4 and 7) was administered to 57 patients with AML in their first relapse. 15 (26\%) patients achieved CR. The median RFS was 11 months. No severe hepatotoxicity was discovered [41]. Several options of combination therapy have also been proposed for R/R AML (Table 1). Salvage therapy with fractionated GO + intermediatedose DA was retrospectively analyzed in 36 high-risk AML patients (median age 54 years) with short CR1 duration ( $<6$ months) or primary refractory disease. The treatment produced a $38.8 \%$ ORR with a $22.2 \%$ CR rate, a 26\% 2-year OS, and a 18.5\% 2-year RFS [24]. A similar study conducted in 24 high-risk AML patients achieved $50 \%$ CR. 1-year OS was 50.7\%. Thirteen patients went on to AlloSCT. Subgroup analysis revealed that the survival was longer for those who received reduced intensity conditioning compared to those undergoing myeloablative conditioning regimen. Therefore, fractionated GO + intermediate-dose DA might be considered as a potential bridge therapy to transplantation while downgrading the toxicity of transplantation regimen [53]. Another effective and tolerable salvage and bridge therapy combination was GO $\left(3 \mathrm{mg} / \mathrm{m}^{2}\right.$ on day 1$)$ plus all-trans retinoic acid, high-dose cytarabine and mitoxantrone. The regimen was studied in a phase II trial (NCT00143975) that enrolled 93 patients aged 18-60 years refractory to one cycle of induction therapy. 57 (61.5\%) patients achieved ORR including 47 (51\%) CR. Among them, 51 patients underwent AlloSCT and had a 4-year OS rate of 49\% [54]. For patients who were unable to tolerate intensive chemotherapies, HMAs appeared to be appropriate alternatives. GO was administered in conjunction with azacytidine in a phase 


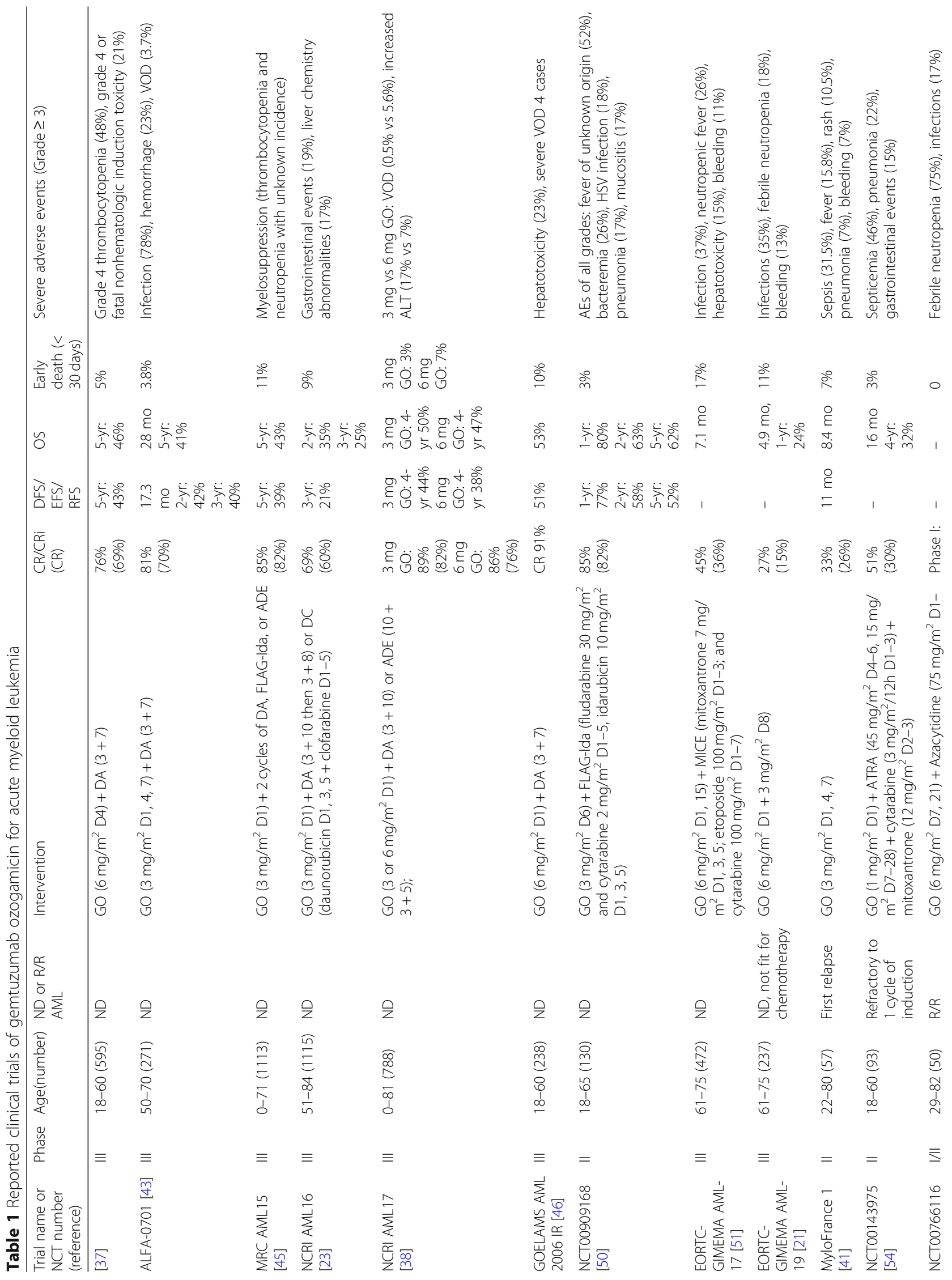




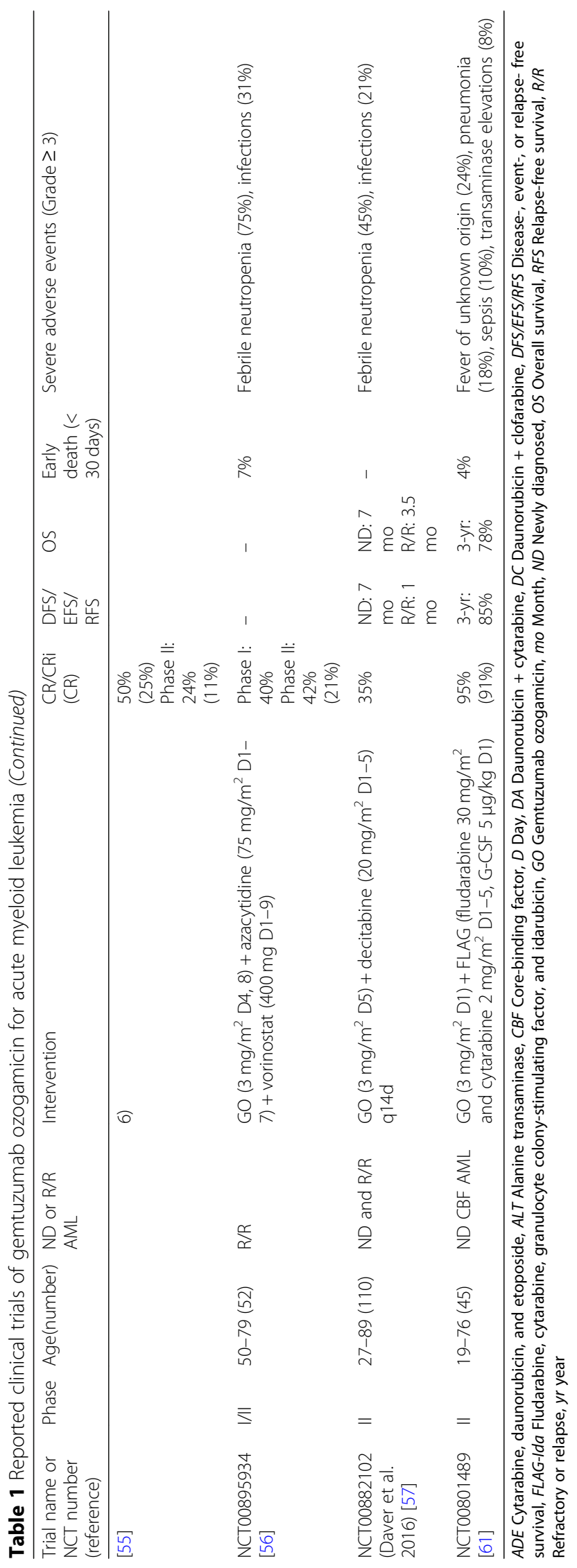


I/II trial (NCT00766116). In the updated report of 50 evaluable patients, 12 (24\%) achieved CR/CRi. A concurrent in vitro study discovered that azacytidine-pretreated AML cells exhibited increased response to GO treatment [55]. In another phase I/II trial (NCT00895934), vorinostat, a histone deacetylase inhibitor, was added to the regimen of GO + azacytidine. 18 (41.9\%) out of the 43 evaluable patients achieved CR/CRi with a median OS of 7.5 months [56]. In addition, decitabine was also evaluated together with GO in older patients with newly diagnosed or R/R AML in a phase II trial (NCT00882102). In the subgroup of R/R AML within 1-year remission, the $\mathrm{CR} / \mathrm{CRi}$ rate was $18 \%$ and the median OS was 3.5 months, while in the subgroup of newly diagnosed AML, the CR/ CRi rate was $45 \%$ and the median OS was 7 months. Therefore, GO + decitabine was a good option for patients who are not suitable for intensive chemotherapy [57]. For patients suffering from relapse after AlloSCT, a 4-day course of $1.0 \mathrm{~g} / \mathrm{m}^{2}$ ARA-C followed by 1 -day of $9 \mathrm{mg} / \mathrm{m} 2$ $\mathrm{GO}$ was reported in one retrospective study. The regimen provided a short-term disease control (ORR 60\%, median OS 103 days, median EFS 76 days) with manageable toxicities [58]. A number of ongoing trials of GO in AML patients were listed in Table 2.

\section{Factors affecting the response to $\mathrm{GO}$}

It is important to note that the clinical benefits of adding GO to standard induction regimen on EFS and RFS were restricted to patients with favorable or intermediate-risk cytogenetics [40, 43]. Aside from cytogenetics, CD33 was another independent biomarker predicting the clinical outcome of GO treatment for adult AML patients. Patients with higher expression of CD33 generally derived the most benefit from GO [59, 60]. NPM1 and FLT3-ITD mutations often increased in prevalence with high CD33 levels, but their impact on the effect of GO varied between studies [40, 47]. Although low expression of CD33 was less likely to benefit from GO, a subgroup of patients with core-binding factor (CBF)-AML showed dramatic response to GO [22]. However, it is important to note that CBF-AML can respond well to high-dose induction regimen alone. In one study (NCT00801489), 45 patients with CBF-AML who received GO in combination with FLAG (FLAG-GO) as a front-line therapy achieved a 75\% ORR, with a 3-year OS and RFS of 78 and $85 \%$ respectively [61]. Encouraging response and outcome were also seen in CBF-AML patients treated with FLAG-Ida + GO [62]. Single nucleotide polymorphism (SNP) in CD33 gene appears to play a role in AML responses to GO. One typical example was rs12459419 $\mathrm{C}>\mathrm{T}$ in the splice enhancer region which produces a truncated form of CD33. It has been reported that patients aged 0-29 with CC genotype, but not CT or TT genotype, for rs12459419 showed a substantial response to GO with low relapse risk and high DFS [63]. However uncertainties about the role of rs12459419 genotype in GO-based therapy still existed since similar correlation failed to be reproduced by either in vitro studies or a

Table 2 Ongoing clinical trials of gemtuzumab ozogamicin for acute myeloid leukemia

\begin{tabular}{|c|c|c|c|c|}
\hline NCT number & Phase & Conditions & Interventions & Recruitment \\
\hline NCT03727750 & IV & $\mathrm{CD} 33+\mathrm{R} / \mathrm{R}$ AML & Evaluate the QTc, pharmacokinetics, safety of GO & $\begin{array}{l}\text { Not yet } \\
\text { recruiting }\end{array}$ \\
\hline NCT03374332 & $\|$ & R/R AML & $\mathrm{GO}(\mathrm{D} 1,4,7)$ followed by non-engraftment donor leukocyte infusion & $\begin{array}{l}\text { Not yet } \\
\text { recruiting }\end{array}$ \\
\hline NCT03737955 & $\|$ & AML with MRD & $\mathrm{GO}(\mathrm{D} 1,4,7)$ & Recruiting \\
\hline NCT02473146 & $\|/\|$ & Elderly AML patients & $\mathrm{GO}(\mathrm{D} 1,4)+$ cytarabine $(\mathrm{D} 1-7)$ vs idarubicin $(\mathrm{D} 1-3)+$ cytarabine (D1-7) & Recruiting \\
\hline NCT03672539 & $\|$ & R/R AML & GO + CPX-351 (liposome-encapsulated daunorubicin-cytarabine) & Recruiting \\
\hline NCT02221310 & $\|$ & High risk CD33+ AML/MDS & $\mathrm{GO}+$ busulfan + cyclophosphamide followed by ASCT & Recruiting \\
\hline NCT03839446 & $\|$ & $\begin{array}{l}\text { AML refractory to initial standard } \\
\text { induction }\end{array}$ & $\mathrm{GO}+$ mitoxantrone + etoposide & Recruiting \\
\hline NCT02117297 & $\|$ & Average risk AML/MDS & ASCT followed by GO (D3, 56 post transplatation) & Recruiting \\
\hline NCT03848754 & । & $\mathrm{R} / \mathrm{R} \mathrm{AML}$ & $\mathrm{GO}(\mathrm{D} 1,4,7)+$ Pracinostat & Recruiting \\
\hline NCT03531918 & $|/| \mid$ & $\begin{array}{l}\text { ND AML or high-grade myeloid } \\
\text { neoplasm }\end{array}$ & $\mathrm{GO}+\mathrm{G}-\mathrm{CSF}+$ Cladribine + Cytarabine + Mitoxantrone & Recruiting \\
\hline NCT03900949 & । & ND FLT-3 mutated AML & $\mathrm{GO}(\mathrm{D} 1,4,7)+\mathrm{DA}(3+7)+$ midostaurin $(\mathrm{D} 8-21)$ & Recruiting \\
\hline NCT00801489 & $\|$ & ND AML and high-risk MDS & $\begin{array}{l}\mathrm{GO}+\text { fludarabine phosphate + cytarabine + filgrastim-sndz + idarubicin } \\
\text { hydrochloride }\end{array}$ & Recruiting \\
\hline NCT03390296 & $|/| \mid$ & $\mathrm{R} / \mathrm{R} \mathrm{AML}$ & $\mathrm{GO}+$ azacytidine + venetoclax or avelumab & Recruiting \\
\hline NCT01409161 & $\|$ & ND acute promyelocytic leukemia & Tretinoin + Arsenic Trioxide \pm GO & Recruiting \\
\hline
\end{tabular}

GO Gemtuzumab ozogamicin, ASCT Allogenic stem cell transplantation, DA Daunorubicin + cytarabine, G-CSF Granulocyte colony stimulating factor, MDS Myelodysplastic syndrome, MRD Measurable residual disease, $N D$ Newly diagnosed, $R / R$ Refractory or relapse 
subsequent study conducted in young adults aged 13-69 [64-66]. New SNPs of other biomarkers are still being explored. Recently rs1045642 $\mathrm{C}>\mathrm{T}$ of $A B C B 1$ encoding the drug-transporter PgP-1 was shown to correlate with a better outcome in patients with a CT/TT genotype compared to CC genotype [67]. In addition, it has been reported that higher expression of ATP binding cassette transporter 3 (ABCA3) and mutation in HFE gene encoding human hemochromatosis protein both independently predicted resistance to the treatment of fractionated GO plus intensive chemotherapy. This was attributed to impaired CD33 internalization and drug sequestration in lysosomes or endosomes $[68,69]$. Another recent study discovered that PP242, a mTORC1/2 kinase inhibitor, was able to potentiate the cytotoxicity of GO by inducing lysosomal activation and progression of cell cycle, which gives new insights into optimizing the response to GO [70].

\section{Safety and toxicity}

The most common toxicity of GO was myelosuppression, notably persistent thrombocytopenia and neutropenia. According to ALFA-0701, grade $\geq 3$ hemorrhage due to a longer duration of treatment-induced thrombocytopenia was more frequently encountered among $\mathrm{GO}+\mathrm{DA}$ recipients compared to DA-only recipients [30 (22.9\%) vs. 13 $(9.5 \%)]$. The average time to platelet count recovery was significantly longer in GO-treated patients (25 vs 21 days). Infections associated with febrile neutropenia represented one of the major causes of early death. But the incidence was similar between patients treated with or without GO [102 (77.9\%) vs $106(77.4 \%)]$, so was the median time to neutrophil count recovery ( 22 vs 22 days). Frequent monitoring and treatment interruption were often required when severe hematologic events occurred [43]. Another drug-specific AE related to GO therapy was hepatotoxicity, including the development of veno-occlusive disease (VOD), also known as sinusoidal obstruction syndrome (SOS), especially after AlloSCT. But lower GO dose (3 $\mathrm{mg} / \mathrm{m}^{2}$ ) with a fractionated regimen significantly reduced the risk of VOD. As reported in ALFA-0701, the incidence of VOD did not significantly differ between the GO and control arm [6 (4.6\%) vs $2(1.5 \%), p=0.165]$, nor did the result of liver chemistry abnormalities [43]. In another study, out of 146 patients undergoing AlloSCT previously treated with GO, 11 (8\%) developed VOD after transplantation, with death in 3 patients, comparable to the incidence of historical cohorts of patients not receiving $\mathrm{GO}$ [71]. Prophylaxis of VOD for high-risk patients with agents such as recombinant human soluble thrombomodulin might further lower the risk [72]. Currently a phase IV study has been initiated aiming at providing more detailed information about the pharmacokinetics and safety of GO (NCT03727750).

\section{Novel ADCs under development for AML}

Several novel ADCs featured by modified structure or new target antigens are currently under development for AML (Table 3).

\section{Anti-CD33 ADCs}

Vadastuximab talirine (SGN-CD33A)

SGN-CD33A is a novel anti-CD33 mAb conjugated to 2 molecules of pyrrolobenzodiazepine (PBD) dimers via a protease-cleavable maleimidocaproyl-valinealanine dipeptide linker on engineered cysteine residues. The engineering technique creates a highly homogenous ADC with a controlled drug-antibody ratio. SGN-CD33A is highly stable in circulation with relatively less off-target toxicity compared to GO. PBD dimer damages DNA by inducing DNA crosslinking after binding to the minor groove [73].

Single-agent SGN-CD33A demonstrated efficacy and a tolerable toxicity profile for AML. In a dose-escalation phase I trial (NCT01902329), $40 \mu \mathrm{g} / \mathrm{kg}$ was identified as the recommended phase 2 dose (RP2D). 14 (54\%) out of 27 elderly patients with previously untreated AML achieved CR/CRi [74]. In another dose-escalation phase I trial (NCT01902329), 131 AML patients (aged 73 on average) received either a single dose (range 5-60 $\mu \mathrm{g} / \mathrm{kg}$ ) of SGNCD33A on day 1 or a dose of $20 \mu \mathrm{g} / \mathrm{kg}$ on days 1 and 4 of a 21-day treatment cycle for a maximum of 2 cycles. This study also defined a single intravenous dose

Table 3 Novel antibody-drug conjugates for acute myeloid leukemia

\begin{tabular}{lllll}
\hline Drug name & Target & Payload & Linker & Development stage \\
\hline Vadastuximab talirine (SGN-CD33A) & CD33 & PBD dimer & Dipeptide linker (protease-cleavable) & Phase III \\
IMGN779 & CD33 & DGN462 & Disulfide linker & Phase I \\
AVE9633 (huMy9-6-DM4) & CD33 & DM4 & Disulfide linker & Phase I (terminated) \\
IMGN632 & CD123 & IGN & Dipeptide linker (protease-cleavable) & Phase I \\
SGN-CD123A & CD123 & PBD dimer & Dipeptide linker (protease-cleavable) & Phase I (terminated) \\
CLT030 & CLL-1 & IQB & Dipeptide linker (protease-cleavable) & Preclinical \\
Anti-CLL-1 ADC & CLL-1 & PBD dimer & Disulfide linker & Preclinical \\
\hline
\end{tabular}

DM4 N20-deacetyl-N20-(4-mercapto-4-methyl-1-oxopentyl)maytansine, IGN Indolinobenzodiazepine pseudodimer, IQB Isoquinolidinobenzodiazepine, PBD Pyrrolobenzodiazepine 
of $40 \mu \mathrm{g} / \mathrm{kg}$ on day 1 as RP2D. At this dose, $5(28 \%)$ out of 18 patients obtained $\mathrm{CR} / \mathrm{CRi}$, with bone marrow blast clearance observed in 8 (44\%) patients. Additionally, subgroup analysis showed that 15 (56\%) out of the 27 patients with previously untreated AML achieved CR/ CRi with bone marrow blast clearance observed in 19 (70\%) patients. Overall, there was an 8\% 30-day mortality rate. Myelosuppression was the most common AE. Median time to full count recovery was 6.4 weeks for neutrophils $(\geq 1000 / \mu \mathrm{L})$ and 10.6 weeks for platelets $(\geq 100,000 / \mu \mathrm{L})$ in patients across all dose levels who achieved CR/CRi. Other AEs included fatigue, nausea, and diarrhea. No significant risk of VOD was reported [75].

SGN-CD33A was explored in combination with the ' 3 + 7' DA induction chemotherapy in 42 patients with newly diagnosed AML in a phase I trial (NCT02326584). The recommended SGN-CD33A dosing schedule in this combination regimen was $20 \mu \mathrm{g} / \mathrm{kg}$ on day 1 and $10 \mu \mathrm{g} /$ $\mathrm{kg}$ on day 4 . The CR/CRi rate was $78 \% .74 \%$ of the CR/ Cri patients achieved negative MRD. All patients experienced grade $\geq 3$ myelosuppression with a median time to neutrophil and platelet count recovery of 4.7 and 5 weeks respectively. No 30-day mortality or significant hepatotoxicity was observed [76]. In another study, HMA was reported to be able to enhance the cytotoxicity of SGN-CD33A by facilitating DNA binding of PBD and upregulating CD33 expression [77]. In this study, a $10 \mu \mathrm{g} / \mathrm{kg}$ dose of SGN-CD33A was added every 4 weeks on the last day of a HMA regimen (either a 7-day regimen of azacitidine or a 5-day regimen of decitabine) for a median treatment duration of 19.3 weeks in 53 newly diagnosed AML patients (average age 75 ) who were unfit for or declined intensive chemotherapy in a phase I trial (NCT01902329). 70\% of patients experienced CR/CRi with a $74 \%$ blast clearance rate and a median OS and RFS of 11.3 and 7.7 months respectively. Similar activity was observed across both low- and high-risk subpopulations. The response rate appeared to be increased as compared to the historical data of HMA monotherapy, but there was also a higher risk of grade $\geq 3$ myelosuppression. Median time to neutrophil and platelet count recovery was 10.6 and 10.1 weeks respectively. The 30-day mortality rate was $2 \%$ [78]. This has led to a phase III trial (CASCADE, NCT02785900) comparing HMA with or without SGN-CD33A in elderly patients with newly diagnosed AML. However, the study was prematurely terminated because of a high rate of death including fatal infections in the SGN-CD33A containing group.

In the post-remission setting, SGN-CD33A combined with high-dose cytarabine seemed to provide an effective consolidation therapy according to a phase $1 \mathrm{~b}$ doseescalation study (NCT02326584). GO was given on day 1 of a 28-day cycle for a median of 2 cycles in combination with high-dose cytarabine. Twenty microgram per kilogram was identified as the MTD. Of the 19 evaluable patients in their first remission, 15 (79\%) maintained remission, and 18 (95\%) patients were alive, and 9 patients (43\%) went on to receive AlloSCT. All patients experienced grade $\geq 3$ myelosuppression, but no 60-day mortality was detected. The same study also evaluated another group of patients in remission and had completed planned post-remission therapies including AlloSCT. Five microgram per kilogram of GO was administered as a single agent on day 1 of a 6-week cycle for a median of 3 cycles. 15 (75\%) out of the 20 evaluable patients were able to maintain remission, suggesting single-agent SGN-CD33A to be a good option for AML maintenance therapy. There was no dose limiting toxicity (DLT). Myelosuppression and mild nonhematologic toxicities were reported but were generally manageable [79]. Further randomized large clinical trials are warranted to confirm these results.

\section{IMGN779}

IMGN779 comprises a humanized anti-CD33 mAb conjugated via a cleavable disulfide linker to DGN462, a novel DNA-alkylating agent. Preclinical studies revealed that IMGN779 was highly active against AML cell lines and LSCs both in vitro and in vivo, especially cells from patients with FLT3-ITD mutation while sparing normal hematopoietic stem cells (HSC), suggesting a potentially lower risk of myelosuppression [80, 81]. There were also studies showing that combining IMGN779 with other agents such as cytarabine or olaparib, a PARP Inhibitor, significantly enhanced anti-tumor activity in preclinical models of AML $[82,83]$. The promising results of preclinical studies have led to an ongoing dose-escalation phase I trial (NCT02674763) in 50 patients with $\mathrm{R} / \mathrm{R}$ CD33+ AML. IMGN779 was administered in either every 2-week (36 patients; dose range: $0.39-1.5 \mathrm{mg} / \mathrm{kg}$ ) or a weekly (14 patients; dose range: $0.39-0.54 \mathrm{mg} / \mathrm{kg}$ ) schedule for a 28-day cycle. Interim results showed that the most frequent SAEs were febrile neutropenia (40\%), bacteremia (22\%), and pneumonia $(20 \%)$. No DLT or drug-related deaths have been observed in either schedule. Overall, 11 (41\%) out of 27 patients with measurable circulating blasts experienced a $>30 \%$ reduction in bone marrow blasts. Further escalation of the dosing schedules is currently ongoing to optimize the clinical response $[84,85]$.

\section{AVE9633 (huMy9-6-DM4)}

AVE9633 is a humanized anti-CD33 IgG1 mAb conjugated to DM4 via a disulfide linker. DM4 is a maytansinoid derivative that binds to tubulin and impede microtubule assembly, leading to G2/M cell cycle arrest and subsequent cell apoptosis. Several phase I trials have been conducted to test AVE9633 in adult patients with 
R/R AML. Even though no significant risk of myelosuppression was observed, no obvious clinical efficacy was noted since only two CR/CRi were reported out of 54 patients $[86,87]$. No further clinical trials have been initiated so far.

\section{Anti-CD123 ADCs}

CD123 is the $\alpha$ chain of the interleukin-3 receptor (IL3R), which forms a heterodimer with the $\beta$ subunit of the IL-3R [88]. CD123 is expressed on most AML tumor cells at a higher level compared to normal hematopoietic progenitors [89]. It has also been found selectively expressed on LSCs [90]. Therefore, CD123 represents a promising target for AML. One CD123-targeted agent that entered phase II development was SL-401, a recombinant fusion protein composed of a human IL-3 and a truncated diphtheria toxin [91]. Interim result from an ongoing phase I/II trial (NCT02270463) conducted in high-risk AML patients in remission showed that out of $7 \mathrm{MRD}+$ patients who received SL-401 at recommended doses, 1 subsequently went on to AlloSCT, and 2 remained in remission at $3+$ and $4+$ months. SL-401 was well tolerated [92]. Several ADCs targeting CD123 are in clinical development and detailed as the following.

\section{IMGN632}

IMGN632 comprises a humanized anti-CD123 mAb conjugated, via a dipeptide linker, to an indolinobenzodiazepine pseudodimer (IGN) class of cytotoxic payload, a newly developed DNA-alkylating agent. IMGN632 demonstrated an abundant antitumor activity against AML cell lines with or without poor prognostic biomarkers (FLT3-ITD, MDR1, TP53, etc.) and in multiple AML xenograft models, including one model which appeared to be resistant to azacitidine and cytarabine $[93,94]$. One study evaluated the effect of combination of GO and IMGN632 on bone marrow cells from 17 AML patients. The bone marrow leukemia cells from all the 17 patients were highly sensitive to IMGN632 at a concentration 150fold lower than the one at which normal progenitors were affected, whereas only 6 out of 17 patient samples were sensitive to GO at the concentration that did not impact normal progenitors, suggesting that IMGN632 has a superior therapeutic window over GO in AML and might be a novel CD123 targeted ADC with limited myelosuppression [93]. IMGN632 was studied in combination with a PARP inhibitor in a preclinical model and the combination synergistically enhanced the anti-leukemic effect [95].

Given the encouraging result of preclinical and early clinical studies, phase I trials of IMGN632 (NCT03386513) are initiated in patients with R/R AML and other CD123+ hematologic malignancies. Interim results showed that among 12 evaluable patients with R/R AML, 4 (33\%) achieved CR/CRi. No DLTs have been noted at doses up to
$0.18 \mathrm{mg} / \mathrm{kg}$. The most frequently encountered treatmentemergent AEs (TEAE) of any grades were primarily gastrointestinal (diarrhea, nausea; 25-42\%), hematologic (febrile neutropenia; 42\%), or vascular (peripheral edema, hypotension, sinus tachycardia; $25-33 \%)$. The most common SAEs were febrile neutropenia (42\%) and lung infection (25\%), but none of these events were considered related to IMGN632 and no discontinuation of therapy due to AEs have occurred [96].

\section{SGN-CD123A}

SGN-CD123A is composed of a humanized anti-CD123 $\mathrm{mAb}$ with a PBD dimer attaching to an engineered cysteine residue on each one of the two heavy chains via a protease-cleavable dipeptide linker. Preclinical studies showed that SGN-CD123A demonstrated anti-tumor activities against AML cell lines and primary samples from AML patients with or without adverse cytogenetic profiles or FLT3 mutations. SGN-123A induced durable CR in multiple AML xenograft models [97, 98]. However the first in-human phase I trial (NCT02848248) was terminated in May 2018 because of safety concerns in AML patients.

\section{Anti-CLL1 ADCs}

Human C-type lectin-like molecule-1 (CLL-1), also known as CLEC12A or MICL, is a transmembrane glycoprotein, highly expressed on AML blast cells and LSCs. Different from CD33 and CD123, CLL-1 is completely absent on normal HSCs, making it an ideal therapeutic target for AML [99]. CD3/CLL-1 bispecific IgG antibody (MCLA-117) is currently under a phase I study for patients with newly diagnosed or $R / R$ AML (NCT03038230) [100]. CD123/CLL-1 chimeric antigen receptor (CAR)-T cells have reached phase III development for patients with R/R AML (NCT03631576) [101].

The first anti-CLL-1 ADC contained a PBD dimer conjugated via a disulfide linker. It demonstrated robust activities at depleting tumor cells in AML xenograft models. In a study of cynomolgus monkey model, neutropenia was the major DLT. No obvious off-target toxicity was observed at the dose that can deplete neutrophils and monocytes [102]. CLT030 is an ADC with a humanized anti-CLL1 mAb site-specifically conjugated to two molecules of isoquinolidinobenzodiazepine (IQB), a novel DNA cross-linker, through a cleavable dipeptide linker. CLT030 demonstrated robust activities in inhibiting in vitro LSC colony formation and reducing in vivo tumor cell survival in AML xenograft models. CLT030 had only limited effect on the normal differentiation of healthy HSCs into various lineages [103]. Clinical studies of anti-CLL-1 ADCs are yet to be done. 


\section{Considerations in using GO for AML therapy}

GO as the first approved CD33-directed ADC is indicated for the treatment of newly-diagnosed CD33+ $(>=$ $1 \%)$ adult AML patients as well as for relapsed or refractory CD33+ pediatric (2 years and older) and adult AML patients. There have been several newly approved agents and regimens for AML therapy in the past 2 years [104]. A variety of factors should be considered for selection of an induction regimen, such as age (younger or older than 60), co-morbidities (cardiac functions as well as other vital organ functions), risk stratifications including cytogenetic abnormalities, genetic mutations such as the targetable mutations FLT3+, IDH1+, or IDH2+. In addition, it is also important to know whether the AML has any myelodysplasia-related changes or is therapyrelated. Since one particular adverse event associated with GO is liver function abnormality /VOD, it is important to pay attention to liver toxic medications, and hepatitis history.

\section{Conclusion}

GO is the first ADC approved by FDA for induction therapy of AML. No randomized data are available yet supporting the addition of GO in consolidation or maintenance therapy. Optimal dose and schedule of GO in combination regimens are still being determined. New ADCs targeting CD33, CD123 and CLL-1 (SGN-CD33A, IMGN779, IMGN632, CLT030) are under active development. It is foreseeable that the treatment landscape of AML will likely continue to expand and evolve with more ADCs being developed and approved.

\section{Abbreviations}

ADC: Antibody-drug conjugate; DLT: Dose-limiting toxicity; MTD: Maximal tolerated dose

\section{Acknowledgements}

$\mathrm{DL}$ is a professor of medicine, Department of Medicine, New York Medical College and Westchester Medical Center, Valhalla, NY 10595, USA.

\section{Authors' contributions}

$\mathrm{DL}$ designed the study. DL and BY drafted the manuscript. All authors participated in the revision of the manuscript. Both authors read and approved the final manuscript.

\section{Funding}

There was no funding for this study.

\section{Availability of data and materials}

The material supporting the conclusion of this review has been included within the article.

Ethics approval and consent to participate

This is not applicable for this review.

\section{Consent for publication}

This is not applicable for this review.

\section{Competing interests}

The authors declare that they have no competing interests.

\section{Author details}

${ }^{1}$ Department of Medicine, Lincoln Medical Center, Bronx, NY, USA.

2Department of Medicine, New York Medical College and Westchester Medical Center, Valhalla, NY, USA. ${ }^{3}$ Department of Oncology, The First

affiliated Hospital of Zhengzhou University, Zhengzhou, China.

Received: 18 September 2019 Accepted: 18 October 2019

Published online: 31 October 2019

\section{References}

1. Dohner H, Weisdorf DJ, Bloomfield CD. Acute myeloid leukemia. N Engl J Med. 2015;373(12):1136-52.

2. Ossenkoppele G, Löwenberg B. How I treat the older patient with acute myeloid leukemia. Blood. 2015;125(5):767-74.

3. Pratz KW, Levis M. How I treat FLT3-mutated AML. Blood. 2017;129(5): 565-71.

4. Rowe JM, Tallman MS. How I treat acute myeloid leukemia. Blood. 2010; 116(17):3147-56.

5. Thol F, Schlenk RF, Heuser M, Ganser A. How I treat refractory and early relapsed acute myeloid leukemia. Blood. 2015;126(3):319-27.

6. Wolach O, Stone RM. How I treat mixed-phenotype acute leukemia. Blood. 2015;125(16):2477-85.

7. Short NJ, Rytting ME, Cortes JE. Acute myeloid leukaemia. Lancet. 2018; 392(10147):593-606

8. Wang Y, Xu Y, Li S, Liu J, Xing Y, Xing H, et al. Targeting FLT3 in acute myeloid leukemia using ligand-based chimeric antigen receptor-engineered T cells. J Hematol Oncol. 2018;11(1):60.

9. Saygin C, Carraway HE. Emerging therapies for acute myeloid leukemia. J Hematol Oncol. 2017;10(1):93.

10. Zhao J, Song Y, Liu D. Gilteritinib: a novel FLT3 inhibitor for acute myeloid leukemia. Biomark Res. 2019;7(1):19.

11. Ling $Y$, Xie Q, Zhang Z, Zhang H. Protein kinase inhibitors for acute leukemia. Biomark Res. 2018;6(1):8.

12. Gu R, Yang $X$, Wei H. Molecular landscape and targeted therapy of acute myeloid leukemia. Biomark Res. 2018;6(1):32.

13. Wang ES. Incorporating FLT3 inhibitors in the frontline treatment of FLT3 mutant acute myeloid leukemia. Best Pract Res Clin Haematol. 2019;32(2): 154-62.

14. Cortes J, Perl AE, Dohner H, Kantariian H, Martinelli G, Kovacsovics T, et al. Quizartinib, an FLT3 inhibitor, as monotherapy in patients with relapsed or refractory acute myeloid leukaemia: an open-label, multicentre, single-arm, phase 2 trial. Lancet Oncol. 2018;19(7):889-903.

15. Yang $X$, Wang J. Precision therapy for acute myeloid leukemia. J Hematol Oncol. 2018;11(1):3.

16. Wu M, Li C, Zhu X. FLT3 inhibitors in acute myeloid leukemia. J Hematol Oncol. 2018;11(1):133

17. Fan M, Li M, Gao L, Geng S, Wang J, Wang Y, et al. Chimeric antigen receptors for adoptive T cell therapy in acute myeloid leukemia. J Hematol Oncol. 2017;10(1):151.

18. Lichtenegger FS, Krupka C, Haubner S, Köhnke T, Subklewe M. Recent developments in immunotherapy of acute myeloid leukemia. J Hematol Oncol. 2017;10(1):142.

19. Wei H, Wang Y, Zhou C, Lin D, Liu B, Liu K, et al. Distinct genetic alteration profiles of acute myeloid leukemia between Caucasian and eastern Asian population. J Hematol Oncol. 2018;11(1):18.

20. Das M. Venetoclax with decitabine or azacitidine for AML. Lancet Oncol. 2018;19(12):e672.

21. Amadori S, Suciu S, Selleslag D, Aversa F, Gaidano G, Musso M, et al. Gemtuzumab Ozogamicin versus best supportive Care in Older Patients with Newly Diagnosed Acute Myeloid Leukemia Unsuitable for intensive chemotherapy: results of the randomized phase III EORTC-GIMEMA AML-19 trial. J Clin Oncol. 2016;34(9):972-9.

22. Appelbaum FR, Bernstein ID. Gemtuzumab ozogamicin for acute myeloid leukemia. Blood. 2017;130(22):2373-6.

23. Burnett AK, Russell NH, Hills RK, Kell J, Freeman S, Kjeldsen L, et al. Addition of gemtuzumab ozogamicin to induction chemotherapy improves survival in older patients with acute myeloid leukemia. J Clin Oncol. 2012;30(32): 3924-31.

24. Chantepie SP, Reboursiere E, Mear JB, Gac AC, Salaun V, Benabed K, et al. Gemtuzumab ozogamicin in combination with intensive chemotherapy in 
relapsed or refractory acute myeloid leukemia. Leuk Lymphoma. 2015;56(8): 2326-30.

25. Aujla A, Aujla R, Liu D. Inotuzumab ozogamicin in clinical development for acute lymphoblastic leukemia and non-Hodgkin lymphoma. Biomark Res. 2019;7(1):9.

26. Yu B, Liu D. Antibody-drug conjugates in clinical trials for lymphoid malignancies and multiple myeloma. J Hematol Oncol. 2019;12(1):94.

27. Abdollahpour-Alitappeh M, Lotfinia M, Gharibi T, Mardaneh J, Farhadihosseinabadi B, Larki P, et al. Antibody-drug conjugates (ADCs) for cancer therapy: strategies, challenges, and successes. J Cell Physiol. 2019; 234(5):5628-42.

28. Kovtun YV, Audette CA, Ye Y, Xie H, Ruberti MF, Phinney SJ, et al. Antibodydrug conjugates designed to eradicate tumors with homogeneous and heterogeneous expression of the target antigen. Cancer Res. 2006;66(6): 3214-21.

29. Nejadmoghaddam MR, Minai-Tehrani A, Ghahremanzadeh R, Mahmoudi M, Dinarvand R, Zarnani AH. Antibody-drug conjugates: possibilities and challenges. Avicenna J Med Biotechnol. 2019;11(1):3-23.

30. Damle NK, Frost P. Antibody-targeted chemotherapy with immunoconjugates of calicheamicin. Curr Opin Pharmacol. 2003;3(4):386-90.

31. Pollard JA, Alonzo TA, Loken M, Gerbing RB, Ho PA, Bernstein ID, et al. Correlation of CD33 expression level with disease characteristics and response to gemtuzumab ozogamicin containing chemotherapy in childhood AML. Blood. 2012;119(16):3705-11.

32. Bernstein ID, Singer JW, Andrews RG, Keating A, Powell JS, Bjornson BH, et al. Treatment of acute myeloid leukemia cells in vitro with a monoclonal antibody recognizing a myeloid differentiation antigen allows normal progenitor cells to be expressed. J Clin Invest. 1987;79(4):1153-9.

33. Bernstein ID, Singer JW, Smith FO, Andrews RG, Flowers DA, Petersens J, et al. Differences in the frequency of normal and clonal precursors of colony-forming cells in chronic myelogenous leukemia and acute myelogenous leukemia. Blood. 1992;79(7):1811-6.

34. Sievers EL, Appelbaum FR, Spielberger RT, Forman SJ, Flowers D, Smith FO, et al. Selective ablation of acute myeloid leukemia using antibody-targeted chemotherapy: a phase I study of an anti-CD33 calicheamicin immunoconjugate. Blood. 1999:93(11):3678-84.

35. Norsworthy KJ, Ko CW, Lee JE, Liu J, John CS, Przepiorka D, et al. FDA approval summary: Mylotarg for treatment of patients with relapsed or refractory CD33-positive acute myeloid leukemia. Oncologist. 2018;23(9): 1103-8.

36. Sievers EL, Larson RA, Stadtmauer EA, Estey E, Lowenberg B, Dombret $H$, et al. Efficacy and safety of gemtuzumab ozogamicin in patients with CD33positive acute myeloid leukemia in first relapse. J Clin Oncol. 2001;19(13): 3244-54.

37. Petersdorf SH, Kopecky KJ, Slovak M, Willman C, Nevill T, Brandwein J, et al. A phase 3 study of gemtuzumab ozogamicin during induction and postconsolidation therapy in younger patients with acute myeloid leukemia. Blood. 2013;121(24):4854-60.

38. Burnett A, Cavenagh J, Russell N, Hills R, Kell J, Jones G, et al. Defining the dose of gemtuzumab ozogamicin in combination with induction chemotherapy in acute myeloid leukemia: a comparison of $3 \mathrm{mg} / \mathrm{m} 2$ with 6 $\mathrm{mg} / \mathrm{m} 2$ in the NCRI AML17 trial. Haematologica. 2016;101(6):724-31.

39. Fostvedt LK, Hibma JE, Masters JC, Vandendries E, Ruiz-Garcia A. Pharmacokinetic/ Pharmacodynamic modeling to support the re-approval of Gemtuzumab Ozogamicin. Clin Pharmacol Ther. 2019;106(5):1006-17.

40. Castaigne S, Pautas C, Terre C, Raffoux E, Bordessoule D, Bastie JN, et al. Acute leukemia French a: effect of gemtuzumab ozogamicin on survival of adult patients with de-novo acute myeloid leukaemia (ALFA-0701): a randomised, open-label, phase 3 study. Lancet. 2012;379(9825):1508-16.

41. Taksin AL, Legrand O, Raffoux E, de Revel T, Thomas X, Contentin N, et al. High efficacy and safety profile of fractionated doses of Mylotarg as induction therapy in patients with relapsed acute myeloblastic leukemia: a prospective study of the alfa group. Leukemia. 2007;21(1):66-71.

42. Jen EY, Ko CW, Lee JE, Del Valle PL, Aydanian A, Jewell C, et al. FDA approval: Gemtuzumab Ozogamicin for the treatment of adults with newly diagnosed CD33-positive acute myeloid leukemia. Clin Cancer Res. 2018; 24(14):3242-6.

43. Lambert J, Pautas $C$, Terre $C$, Raffoux E, Turlure P, Caillot D, et al. Gemtuzumab ozogamicin for de novo acute myeloid leukemia: final efficacy and safety updates from the open-label, phase III ALFA-0701 trial. Haematologica. 2019;104(1):113-9.
44. Pautas C, Raffoux E, Lambert J, Legrand O, Benner RJ, Vandendries ER, et al. Outcomes following hematopoietic stem cell transplantation in patients treated with chemotherapy with or without Gemtuzumab Ozogamicin for acute myeloid leukemia. Blood. 2018;132(Suppl 1):28.

45. Burnett AK, Hills RK, Milligan D, Kjeldsen L, Kell J, Russell NH, et al. Identification of patients with acute myeloblastic leukemia who benefit from the addition of gemtuzumab ozogamicin: results of the MRC AML15 trial. J Clin Oncol. 2011;29(4):369-77.

46. Delaunay J, Recher C, Pigneux A, Witz F, Vey N, Blanchet O, et al. Addition of Gemtuzumab Ozogamycin to chemotherapy improves event-free survival but not overall survival of AML patients with intermediate cytogenetics not eligible for allogeneic transplantation. Results of the GOELAMS AML 2006 IR Study. Blood. 2011;118(21):37-8.

47. Hills RK, Castaigne S, Appelbaum FR, Delaunay J, Petersdorf S, Othus M, et al. Addition of gemtuzumab ozogamicin to induction chemotherapy in adult patients with acute myeloid leukaemia: a meta-analysis of individual patient data from randomised controlled trials. Lancet Oncol. 2014;15(9): 986-96

48. Zhang CC, Yan Z, Pascual B, Jackson-Fisher A, Huang DS, Zong Q, et al. Gemtuzumab Ozogamicin (GO) inclusion to induction chemotherapy eliminates leukemic initiating cells and significantly improves survival in mouse models of acute myeloid leukemia. Neoplasia. 2018;20(1):1-11.

49. Konopleva MY, Jordan CT. Leukemia stem cells and microenvironment: biology and therapeutic targeting. J Clin Oncol. 2011;29(5):591-9.

50. Candoni A, Papayannidis C, Martinelli G, Simeone E, Gottardi M, lacobucci I, et al. Flai (fludarabine, cytarabine, idarubicin) plus low-dose Gemtuzumab Ozogamicin as induction therapy in CD33-positive AML: final results and long term outcome of a phase II multicenter clinical trial. Am J Hematol. 2018;93(5):655-63.

51. Amadori S, Suciu S, Stasi R, Salih HR, Selleslag D, Muus $P$, et al. Sequential combination of gemtuzumab ozogamicin and standard chemotherapy in older patients with newly diagnosed acute myeloid leukemia: results of a randomized phase III trial by the EORTC and GIMEMA consortium (AML-17). J Clin Oncol. 2013;31(35):4424-30.

52. Ashaye AO, Khankhel Z, Xu Y, Fahrbach K, Mokgokong R, Orme ME, et al. A comparative evaluation of gemtuzumab ozogamicin + daunorubicincytarabine and other treatments for newly diagnosed acute myeloid leukemia. Future Oncol. 2019;15(6):663-81.

53. Paubelle E, Ducastelle-Lepretre S, Labussiere-Wallet H, Nicolini FE, Barraco F, Plesa A, et al. Fractionated gemtuzumab ozogamicin combined with intermediate-dose cytarabine and daunorubicin as salvage therapy in very high-risk AML patients: a bridge to reduced intensity conditioning transplant? Ann Hematol. 2017:96(3):363-71.

54. Hutter-Kronke ML, Benner A, Dohner K, Krauter J, Weber D, Moessner M, et al. Salvage therapy with high-dose cytarabine and mitoxantrone in combination with all-trans retinoic acid and gemtuzumab ozogamicin in acute myeloid leukemia refractory to first induction therapy. Haematologica. 2016;101(7):839-45.

55. Medeiros BC, Tanaka TN, Balaian L, Bashey A, Guzdar A, Li H, et al. A phase I/II trial of the combination of Azacitidine and Gemtuzumab Ozogamicin for treatment of relapsed acute myeloid leukemia. Clin Lymphoma Myeloma Leuk. 2018;18(5):346-52 e345.

56. Walter RB, Medeiros BC, Gardner KM, Orlowski KF, Gallegos L, Scott BL, et al. Gemtuzumab ozogamicin in combination with vorinostat and azacitidine in older patients with relapsed or refractory acute myeloid leukemia: a phase I/II study. Haematologica. 2014;99(1):54-9.

57. Daver N, Kantarjian H, Ravandi F, Estey E, Wang X, Garcia-Manero G, et al. A phase II study of decitabine and gemtuzumab ozogamicin in newly diagnosed and relapsed acute myeloid leukemia and high-risk myelodysplastic syndrome. Leukemia. 2016;30(2):268-73.

58. Koren-Michowitz M, Maayan H, Apel A, Shem-Tov N, Yerushalmi R, Volchek Y, et al. Salvage therapy with ARA-C and gemtuzumab ozogamicin in AML patients relapsing after stem cell transplantation. Ann Hematol. 2015;94(3):375-8.

59. Olombel G, Guerin E, Guy J, Perrot JY, Dumezy F, de Labarthe A, et al. The level of blast CD33 expression positively impacts the effect of gemtuzumab ozogamicin in patients with acute myeloid leukemia. Blood. 2016;127(17): 2157-60.

60. Khan N, Hills RK, Virgo P, Couzens S, Clark N, Gilkes A, et al. Expression of CD33 is a predictive factor for effect of gemtuzumab ozogamicin at different doses in adult acute myeloid leukaemia. Leukemia. 2017;31(5): 1059-68. 
61. Borthakur G, Cortes JE, Estey EE, Jabbour E, Faderl S, O'Brien S, et al. Gemtuzumab ozogamicin with fludarabine, cytarabine, and granulocyte colony stimulating factor (FLAG-GO) as front-line regimen in patients with core binding factor acute myelogenous leukemia. Am J Hematol. 2014; 89(10):964-8.

62. Gottardi M, Mosna F, de Angeli S, Papayannidis C, Candoni A, Clavio M, et al. Clinical and experimental efficacy of gemtuzumab ozogamicin in core binding factor acute myeloid leukemia. Hematol Rep. 2017;9(3):7029.

63. Lamba JK, Chauhan L, Shin M, Loken MR, Pollard JA, Wang YC, et al. CD33 splicing polymorphism determines Gemtuzumab Ozogamicin response in De novo acute myeloid leukemia: report from randomized phase III Children's oncology group trial AAML0531. J Clin Oncol. 2017;35(23):2674-82.

64. Gale RE, Popa T, Wright M, Khan N, Freeman SD, Burnett AK, et al. No evidence that CD33 splicing SNP impacts the response to GO in younger adults with AML treated on UK MRC/NCRI trials. Blood. 2018;131(4):468-71.

65. Laszlo GS, Beddoe ME, Godwin CD, Bates OM, Gudgeon CJ, Harrington KH, et al. Relationship between CD33 expression, splicing polymorphism, and in vitro cytotoxicity of gemtuzumab ozogamicin and the CD33/CD3 BiTE(R) AMG 330. Haematologica. 2019;104(2):e59-62.

66. Stanchina M, Pastore A, Devlin S, Famulare C, Stein E, Taylor J. CD33 splice site genotype was not associated with outcomes of patients receiving the anti-CD33 drug conjugate SGN-CD33A. J Hematol Oncol. 2019;12(1):85.

67. Rafiee R, Chauhan L, Alonzo TA, Wang YC, Elmasry A, Loken MR, et al. ABCB1 SNP predicts outcome in patients with acute myeloid leukemia treated with Gemtuzumab ozogamicin: a report from Children's oncology group AAML0531 trial. Blood Cancer J. 2019;9(6):51.

68. Ceraulo A, Mint-Mohamed A, Maucort-Boulch D, Paubelle E, Thomas X, Herpe $L$, et al. ABCA3 expression predicts response to Gemtuzumab Ozogamicin in AML. Blood. 2016;128(22).

69. Paubelle E, Marceau A, Zylbersztejn F, Dussiot M, Moura IC, CornilletLefebvre $P$, et al. HFE gene mutation status predicts response to Gemtuzumab Ozogamicin in AML. Blood. 2015;126(23).

70. Maimaitili Y, Inase A, Miyata Y, Kitao A, Mizutani Y, Kakiuchi S, et al. An mTORC1/2 kinase inhibitor enhances the cytotoxicity of gemtuzumab ozogamicin by activation of lysosomal function. Leuk Res. 2018;74:68-74.

71. Battipaglia G, Labopin M, Candoni A, Fanin R, El Cheikh J, Blaise D, et al. Risk of sinusoidal obstruction syndrome in allogeneic stem cell transplantation after prior gemtuzumab ozogamicin treatment: a retrospective study from the acute leukemia working party of the EBMT. Bone Marrow Transplant 2017:52(4):592-9.

72. Yamamoto S, Matsuno R, Sugishita Y, Kaneko R, Okamoto N, Koganesawa M, et al. Sinusoidal obstructive syndrome prophylaxis with recombinant human soluble thrombomodulin is feasible in gemtuzumab ozogamicin-treated patients undergoing allogeneic hematopoietic cell transplantation. Bone Marrow Transplant. 2017:52(7):1068-70.

73. Kung Sutherland MS, Walter RB, Jeffrey SC, Burke PJ, Yu C, Kostner H, et al. SGN-CD33A: a novel CD33-targeting antibody-drug conjugate using a pyrrolobenzodiazepine dimer is active in models of drug-resistant AML. Blood. 2013;122(8):1455-63.

74. Bixby DL, Stein AS, Fathi AT, Kovacsovics TJ, Levy MY, Erba HP, et al. Vadastuximab Talirine monotherapy in older patients with treatment naive CD33-positive acute myeloid leukemia (AML). Blood. 2016;128(22).

75. Stein EM, Walter RB, Erba HP, Fathi AT, Advani AS, Lancet JE, et al. A phase 1 trial of vadastuximab talirine as monotherapy in patients with CD33-positive acute myeloid leukemia. Blood. 2018;131(4):387-96.

76. Erba HP, Levy MY, Vasu S, Stein AS, Fathi AT, Maris MB, et al. A phase $1 \mathrm{~b}$ Study of Vadastuximab Talirine in combination with $7+3$ induction therapy for patients with newly diagnosed acute myeloid leukemia (AML). Blood. 2016;128(22).

77. Sutherland MSK, Yu CP, O'Day C, Alley S, Anderson M, Emmerton K, et al. SGN-CD33A in combination with Hypomethylating agents is highly efficacious in preclinical models of AML. Blood. 2015;126(23).

78. Fathi AT, Erba HP, Lancet JE, Stein EM, Ravandi F, Faderl S, et al. A phase 1 trial of vadastuximab talirine combined with hypomethylating agents in patients with CD33-positive AML. Blood. 2018;132(11):1125-33.

79. Yang J, Ravandi F, Advani A, Vasu S, Walter RB, Faderl S, et al. A phase 1b Study of Vadastuximab Talirine as maintenance and in combination with standard consolidation for patients with acute myeloid leukemia (AML). Blood. 2016;128(22).

80. Whiteman KR, Noordhuis $P$, Walker $R$, Watkins $K$, Kovtun $Y$, Harvey L, et al. The antibody-drug conjugate (ADC) IMGN779 is highly active in vitro and in vivo against acute myeloid leukemia (AML) with FLT3-ITD mutations. Blood. 2014;124(21)

81. Krystal WM, Walker R, Fishkin N, Audette C, Kovtun Y, Romanelli A. IMGN779, a CD33-targeted antibody-drug conjugate (ADC) with a novel DNAalkylating effector molecule, induces DNA damage, cell cycle arrest, and apoptosis in AML cells. Blood. 2015;126(23).

82. Portwood S, Puchalski RA, Walker RM, Wang ES. Combining IMGN779, a novel anti-CD33 antibody-drug conjugate (ADC), with the PARP inhibitor, Olaparib, results in enhanced anti-tumor activity in preclinical acute myeloid leukemia (AML) models. Blood. 2016;128(22).

83. Adams S, Kelly M, McCarthy R, Wilhelm A, Watkins K, Lanieri L, et al. IMGN779, a next generation CD33-targeting ADC, combines effectively with Cytarabine in acute myeloid leukemia (AML) preclinical models, resulting in increased DNA damage response, cell cycle arrest and apoptosis in vitro and prolonged survival in vivo. Blood. 2017:130

84. Cortes JE, Traer E, Wang ES, Erba HP, Blum W, Arana-Yi C, et al. IMGN779, a next-generation CD33-targeting antibody-drug conjugate (ADC) demonstrates initial Antileukemia activity in patients with relapsed or refractory acute myeloid leukemia. Blood. 2017;130.

85. Cortes JE, DeAngelo DJ, Erba HP, Traer E, Papadantonakis N, Arana-Yi C, et al. Maturing clinical profile of IMGN779, a next-generation CD33-targeting antibody-drug conjugate, in patients with relapsed or refractory acute myeloid leukemia. Blood. 2018;132.

86. Legrand $\mathrm{O}$, Vidriales MB, Thomas X, Dumontet C, Vekboff A, Morariu-Zamfir $\mathrm{R}$, et al. An open label, dose escalation study of AVE9633 administered as a single agent by intravenous (IV) infusion weekly for 2 weeks in 4-week cycle to patients with relapsed or refractory CD33-positive acute myeloid leukemia (AML). Blood. 2007;110(11):548a.

87. Lapusan S, Vidriales MB, Thomas X, de Botton S, Vekhoff A, Tang R, et al. Phase I studies of AVE9633, an anti-CD33 antibody-maytansinoid conjugate, in adult patients with relapsed/refractory acute myeloid leukemia. Invest New Drugs. 2012:30(3):1121-31.

88. Guthridge MA, Stomski FC, Thomas D, Woodcock JM, Bagley CJ, Berndt MC, et al. Mechanism of activation of the GM-CSF, IL-3, and IL-5 family of receptors. Stem Cells. 1998;16(5):301-13.

89. Jordan CT, Upchurch D, Szilvassy SJ, Guzman ML, Howard DS, Pettigrew AL, et al. The interleukin-3 receptor alpha chain is a unique marker for human acute myelogenous leukemia stem cells. Leukemia. 2000;14(10):1777-84.

90. Jin L, Lee EM, Ramshaw HS, Busfield SJ, Peoppl AG, Wilkinson L, et al. Monoclonal antibody-mediated targeting of CD123, IL-3 receptor alpha chain, eliminates human acute myeloid leukemic stem cells. Cell Stem Cell. 2009:5(1):31-42.

91. Sun W, Liu H, Kim Y, Karras N, Pawlowska A, Toomey D, et al. First pediatric experience of SL-401, a CD123-targeted therapy, in patients with blastic plasmacytoid dendritic cell neoplasm: report of three cases. J Hematol Oncol. 2018;11(1):61

92. Lane AA, Sweet KL, Wang ES, Donnellan W, Walter RB, Mantzaris I, et al. Results from ongoing phase $1 / 2$ trial of SL-401 as consolidation therapy in patients with acute myeloid leukemia (AML) in remission with minimal residual disease (MRD). Blood. 2017;130.

93. Kovtun Y, Jones G, Audette C, Harvey L, Gerard B, Wilhelm A, et al. A CD123-targeting antibody-drug conjugate (ADC), IMGN632, designed to eradicate acute myeloid leukemia (AML) cells while sparing Normal bone marrow cells. Blood. 2016;128(22).

94. Adams S, Wilhelm A, Harvey L, Bai C, Yoder N, Kovtun Y, et al. IMGN632: a CD123-targeting antibody-drug conjugate (ADC) with a novel DNAalkylating payload, is highly active and prolongs survival in acute myeloid leukemia (AML) xenograft models. Blood. 2016;128(22).

95. Fritz C, Portwood SM, Adams J, Cronin T, Lutgen-Dunckley L, Martens BL, et al. Synergistic anti-leukemic activity of PARP inhibition combined with IMGN632, an anti-CD123 antibody-drug conjugate in acute myeloid leukemia models. Blood. 2018;132.

96. Daver NG, Erba HP, Papadantonakis N, DeAngelo DJ, Wang ES, Konopleva MY, et al. A phase I, first-in-human Study evaluating the safety and preliminary Antileukemia activity of IMGN632, a novel CD123-targeting antibody-drug conjugate, in patients with relapsed/refractory acute myeloid leukemia and other CD123-positive hematologic malignancies. Blood. 2018;132.

97. Sutherland MSK, Yu CP, Walter RB, Westendorf L, Valliere-Douglass J, Pan L, et al. SGN-CD123A, a Pyrrolobenzodiazepine dimer linked anti-CD123 antibody drug conjugate, demonstrates effective anti-leukemic activity in multiple preclinical models of AML. Blood. 2015;126(23). 
98. Li F, Sutherland MK, Yu C, Walter RB, Westendorf L, Valliere-Douglass J, et al. Characterization of SGN-CD123A, a potent CD123-directed antibody-drug conjugate for acute myeloid leukemia. Mol Cancer Ther. 2018;17(2):554-64.

99. Larsen HO, Roug AS, Just T, Brown GD, Hokland P. Expression of the hMICL in acute myeloid leukemia-a highly reliable disease marker at diagnosis and during follow-up. Cytometry B Clin Cytom. 2012;82(1):3-8.

100. Leong SR, Sukumaran S, Hristopoulos M, Totpal K, Stainton S, Lu E, et al. An anti-CD3/anti-CLL-1 bispecific antibody for the treatment of acute myeloid leukemia. Blood. 2017;129(5):609-18.

101. De Togni E, Kim MY, Cooper ML, Ritchey J, O'Neal J, Niswonger J, et al. Chimeric antigen receptor T cells specific for CLL-1 for treatment of Actue myeloid leukemia. Blood. 2018;132.

102. Jiang YP, Liu BY, Zheng Q, Panuganti S, Chen R, Zhu J, et al. CLT030, a leukemic stem cell-targeting CLL1 antibody-drug conjugate for treatment of acute myeloid leukemia. Blood Adv. 2018:2(14):1738-49.

103. Zheng B, Yu SF, Del Rosario G, Leong SR, Lee GY, Vij R, et al. An anti-CLL-1 antibody-drug conjugate for the treatment of acute myeloid leukemia. Clin Cancer Res. 2019;25(4):1358-68

104. Lai C, Doucette K, Norsworthy K. Recent drug approvals for acute myeloid leukemia. J Hematol Oncol. 2019;12(1):100

\section{Publisher's Note}

Springer Nature remains neutral with regard to jurisdictional claims in published maps and institutional affiliations.

Ready to submit your research? Choose BMC and benefit from:

- fast, convenient online submission

- thorough peer review by experienced researchers in your field

- rapid publication on acceptance

- support for research data, including large and complex data types

- gold Open Access which fosters wider collaboration and increased citations

- maximum visibility for your research: over $100 \mathrm{M}$ website views per year

At $\mathrm{BMC}$, research is always in progress.

Learn more biomedcentral.com/submissions 